\title{
Estimation of $V s$ profile using its natural frequency and Rayleigh-wave dispersion characteristics
}

\author{
K. Tokeshi, M. Karkee, and C. Cuadra \\ Department of Architecture and Environment Systems, Akita Prefectural University, Yuri-Honjo, 015-0055 Akita, Japan
}

Received: 30 May 2007 - Revised: 29 August 2007 - Accepted: 3 September 2007 - Published: 2 January 2008

\begin{abstract}
The evaluation of the natural frequency of random $V s$ profiles before analyzing the fundamental Rayleigh-wave dispersion characteristics is proposed in this paper. The inclusion of this parameter optimizes the effectiveness of random inverse searching to estimate $V s$ profiles. To demonstrate this method, a numerical test was performed using the "experimental" Rayleigh-wave dispersion curve obtained for a fictitious TEST site.
\end{abstract}

\section{Introduction}

Highly populated cities in numerous developing countries are facing a high seismic risk. In many cases, the damages caused by earthquakes have been the consequence of the interaction between ground motion and soil-structure interaction; the so-called "site effect". In that respect one wellknown example is the 1985 Mexico City earthquake that caused 60000 casualties. The characteristics of the ground structure, in particular the $V s$ profile: shear wave velocity and thickness of each layer, are very important for earthquake disaster prevention, and the role of geophysical prospecting is preponderant. These geophysical prospecting techniques should be economic, fast and reliable.

One of the most recent techniques for estimating the soil profile is using the characteristics of Rayleigh-wave dispersion. The Rayleigh-wave is a type of surface wave, which is dispersive due to that the phase velocity of Rayleigh-wave varies with frequency. Haskell (1953) showed the basis for calculating the theoretical Rayleigh-wave dispersion on a multilayered media. Nowadays, there are several methods for estimating the Rayleigh-wave dispersion characteristics from ambient vibrations. For example, the high resolution $f-k$ spectral method (Capon, 1969), the SAC method (Toki-

Correspondence to: $\mathrm{K}$. Tokeshi

(tokeshi@akita-pu.ac.jp) matsu, 1995), and the SASW method (Nazarian and Stokoe, 1984), among other methods, are some of the most used techniques. Whichever method is used, the obtained dispersion curve has some variations of phase velocity at each frequency, and this fact should be considered during the inverse analysis process.

Concerning to the inverse analysis of Rayleigh-wave dispersion characteristics, a full systematic search using wide ranges of values for shear-wave velocity and thickness would demand huge computation times, due to the large total number of combinations that increases with the number of layers in the performed analysis. Nowadays, there are several methods, e.g., the Neighbourhood Algorithm (NA) and the Genetic Algorithm (GA) (Sen and Stoffa, 1995). One of fastest methods would be the NA method proposed by Sambridge (1999), which uses a stochastic direct technique for non-linear geophysical inverse problems through multidimensional parameter spaces. However the NA code is not available for personal computers. The random inverse analysis used in this research could be considered as the first generation in the GA to find new and better sets of ranges for the next generation of searching.

\section{Experimental Rayleigh-wave dispersion at fictitious TEST site}

To show the effectiveness of the here presented method, a numerical test was performed on a fictitious TEST site. The physical parameters of each layer are shown in Table 1. The "experimental dispersion", which is actually the theoretical Rayleigh-wave dispersion curve, was calculated using the defined physical parameters of Table 1 (Fig. 1). Only 14 points from a frequency band of $3.4 \sim 7.0 \mathrm{~Hz}$ of this experimental dispersion curve (black points in Fig. 1) were selected for faster evaluation. The criteria used for minimum and maximum limits of the frequency band were (1) that the phase

Published by Copernicus Publications on behalf of the European Geosciences Union. 
Table 1. Physical parameters assumed for TEST site.

\begin{tabular}{ccccc}
\hline Layer & Density $\left(\mathrm{ton} / \mathrm{m}^{3}\right)$ & $V_{P}(\mathrm{~m} / \mathrm{s})$ & $V s(\mathrm{~m} / \mathrm{s})$ & $H(\mathrm{~m})$ \\
\hline 1 & 1.32 & 330 & 150 & 5 \\
2 & 2.06 & 1950 & 240 & 10 \\
3 & 2.06 & 1950 & 380 & 6 \\
4 & 2.19 & 2490 & 930 & 12 \\
5 & 2.28 & 2910 & 1470 & 40 \\
6 & 2.38 & 3500 & 1850 & 30 \\
7 & 2.50 & 3800 & 2500 & $\infty$
\end{tabular}

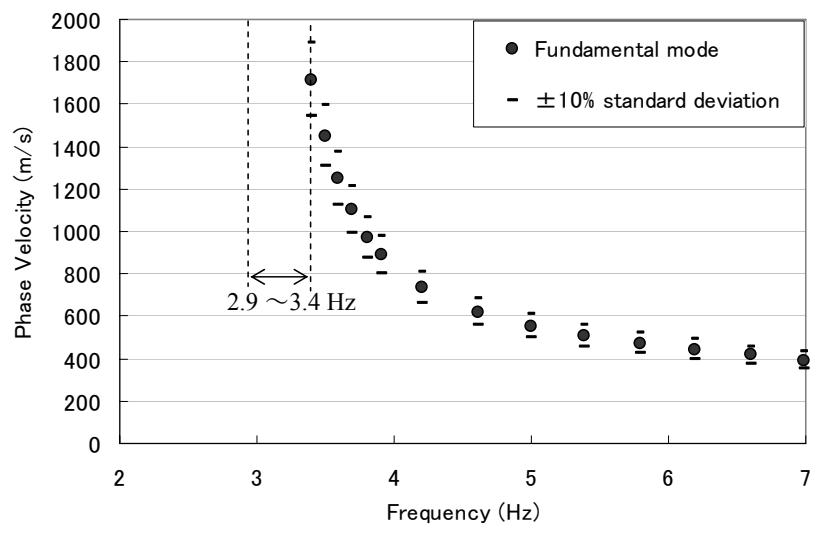

Fig. 1. Experimental Rayleigh-wave dispersion characteristics used as target for estimating $V s$ profile at fictitious TEST site.

velocity for frequencies lower than $3.4 \mathrm{~Hz}$ showed high uncertainty and (2) that the values of phase velocity for frequencies higher than $7.0 \mathrm{~Hz}$ may be affected by higher modes of Rayleigh-waves. A standard deviation $(\sigma= \pm 10 \%)$ of the phase velocity at each frequency (dash lines in Fig. 1) was considered due to the variability of actual Rayleigh-wave dispersion curve.

The random searching for possible $V s$ profiles was carried out through multidimensional parametric spaces. Values of all parameters for all layers were assigned simultaneously with random values within their respective ranges. Table 2 shows the ranges used for Poisson ratio (v), S-wave velocity $(V s)$, and thickness $(H)$ in each layer during inverse analysis. The shear wave velocity and the thickness have strong influence on the characteristics of Rayleigh-wave dispersion.

The P-wave velocity $\left(V_{P}\right)$ in each layer was calculated by Eq. (1).

$V_{P}=V s\left(\frac{1-v}{0.5-v}\right)^{1 / 2}$

And the density $(\rho)$ in each layer was determined by Eq. (2), which is the empirical relation proposed by Gardner et al. (1974).

$\rho=0.31 V_{P}^{0.25}$

where, $\rho$ is in $\left(\mathrm{t} / \mathrm{m}^{3}\right)$ and $V_{P}$ is in $(\mathrm{m} / \mathrm{s})$.
Table 2. Ranges of parameters used for random inverse analysis.

\begin{tabular}{cccc}
\hline Layer & $v$ & $V s(\mathrm{~m} / \mathrm{s})$ & $H(\mathrm{~m})$ \\
\hline 1 & $0.25 \sim 0.49$ & $50 \sim 300$ & $1 \sim 30$ \\
2 & & $100 \sim 500$ & $1 \sim 50$ \\
3 & & $200 \sim 1000$ & $1 \sim 50$ \\
4 & & $200 \sim 2000$ & $1 \sim 100$ \\
5 & & $200 \sim 3000$ & $1 \sim 100$ \\
6 & & $200 \sim 4000$ & $1 \sim 100$ \\
\hline
\end{tabular}

A huge number of trials $(1.26 \times 1023$ combinations $)$ would obtained if the increments of $10 \mathrm{~m} / \mathrm{s}$ for S-wave velocity and $1 \mathrm{~m}$ for thickness are applied in respective parameter ranges of Table 2. So, the full systematic calculation would take a huge computer consuming time.

As one key for optimizing computation time, the value of natural frequency of each random $V s$ profile was calculated before assessing its respective Rayleigh-wave dispersion. Only the $V s$ models whose values for the natural frequency are within a certain frequency band and lower than a certain frequency where the value of phase velocity becomes asymptotic were taken into account for calculating of theoretical fundamental Rayleigh-wave dispersion. The frequency range of $2.9 \sim 3.4 \mathrm{~Hz}$ was chosen as appropriate frequency band for checking the natural frequency of random $V s$ profiles at TEST site (see Fig. 1). In this sense, Fäh et al. (2003) reported that stable parts of the H/V ratio of ambient vibrations are dominated by the ellipticity of the fundamental mode of Rayleigh-wave in the frequency band between the natural frequency of unconsolidated or "soft" sediments and the first minimum of the average H/V ratio. Furthermore, Bonnefoy-Claudet et al. (2006) concluded that the predominant frequency of the $\mathrm{H} / \mathrm{V}$ ratio from synthetic ambient vibrations when sources are on the surface is related to the fundamental mode of Rayleigh-waves. The authors have verified this relationship using their own synthetic ambient vibrations. A detailed description of their numerical simulation is given in Tokeshi et al. (2000).

\section{Results from random inverse analysis}

The total number of trials used for random inverse analysis was 10 millions, which took 1 day to finish calculation. After satisfying the two conditions, the value of fundamental Rayleigh-wave velocity within $\pm 10 \%$ of the experimental phase velocity at each frequency and the value of natural frequency of $V s$ profile within a frequency band lower than the asymptotic frequency of Rayleigh-wave dispersion, all but 62 solutions were rejected and interpreted as possible solutions for $V s$ profiles. Figure 2 shows the 10 best solutions (gray lines), the former $V s$ profile (dashed line), and, the average of the 10 solutions (solid line). The average of $V s$ pro- 


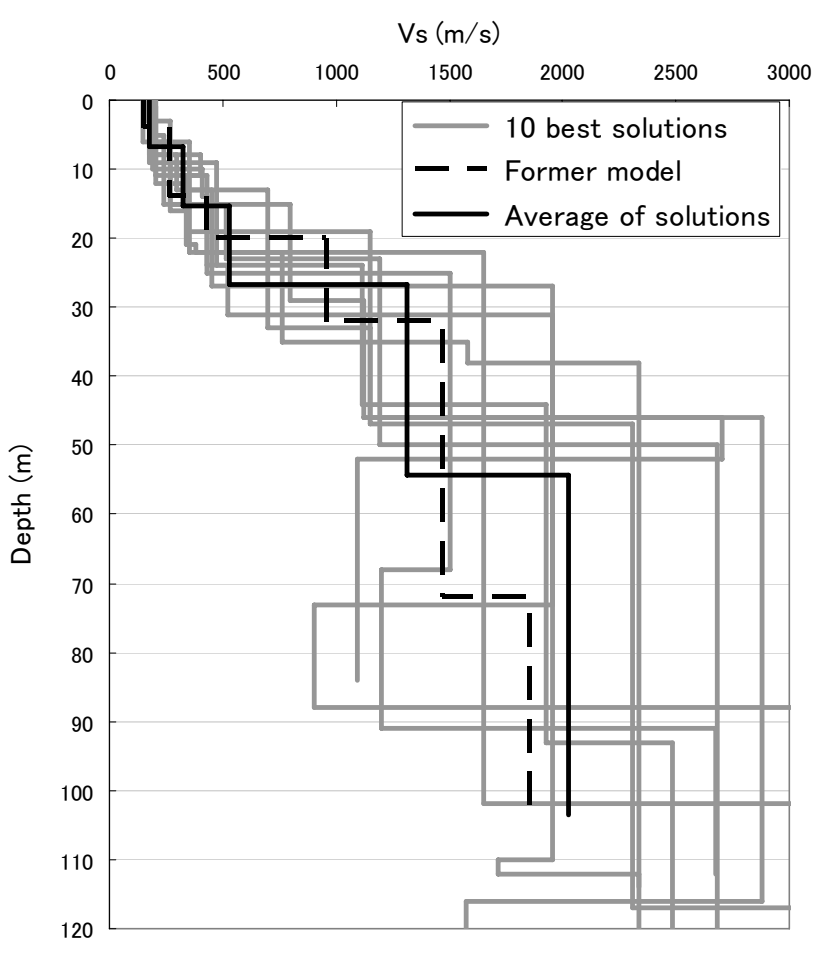

Fig. 2. $V s$ profiles obtained from random inverse analysis of experimental Rayleigh-wave dispersion characteristics.

file was obtained as the average of corresponding values for thicknesses and shear wave velocities of each layer. It is clear that the variation of possible solutions for $V s$ profile increases with depth, but the fitting of average with former $V s$ profile is acceptable.

\section{Conclusions}

For optimizing random inverse analysis, the previous evaluation of the natural frequency of each random $V s$ profile was included, just before calculation of fundamental Rayleighwave dispersion characteristics. One test on the proposed optimization was carried out on a fictitious TEST site, whose physical parameters of each layer were defined beforehand. The theoretical or experimental fundamental Rayleigh-wave dispersion curve obtained at this TEST site was used as the target during random inverse searching.

The conclusions are as follows:

- The inclusion of a previous evaluation of the natural frequency of each random $V s$ profile is an effective tool for optimizing the random inverse searching.

- The variation of $V s$ profiles from possible solutions increases with depth, but the average of possible solutions is acceptable when comparing with the former $V s$ profile model.
Acknowledgements. The authors thank the support of the Japan Society for the Promotion of Science (JSPS): Grants-in-Aid for the Scientific Research, Project No. 18560556.

Edited by: P. Fabian

Reviewed by: two anonymous referees

\section{References}

Bonnefoy-Claudet, A., Cornou C., Bard, P. Y., Cotton, F., Moczo, P., Kristek, J., and Fah, D.: H/V ratio: a tool for site effects evaluation. Results from 1-D noise simulations, Geophys. J. Int., 167, 827-837, 2006.

Capon, J.: High-resolution frequency-wavenumber spectrum analysis, Proc. IEEE, 57(8), 1408-1418, 1969.

Fäh, D., Kind, F., and Giardini D.: Inversion of local S-wave velocity structures from average $\mathrm{H} / \mathrm{V}$ ratios, and their use for the estimation of site-effects, J. Seismol., 7, 449-467, 2003.

Gardner, G. H. F., Gardner, L. W., and Gregory, A. R.: Formation velocity and density; the diagnostic basics for stratigraphic traps, Geophysics, 39, 770-780, 1974.

Haskell, N. A.: The dispersion of surface waves in multilayered media, BSSA, 43, 17-34, 1953.

Nazarian, S. and Stokoe, K. H.: Use of surface waves in pavement evaluation, Transportation Research Record 1070, TRB, National Research Council, 132-144, 1984.

Sambridge, M.: Geophysical inversion with a neighbourhood algorithm I. Searching a parameter space, Geophys. J. Int., 103, 4839-4878, 1999.

Sen, M. K. and Stoffa, P. L.: Global Optimization Methods in Geophysical Inversion, Advances in Exploration Geophysics, 4, Elsevier Science Ltd., 1995.

Tokeshi, J. C., Sugimura, Y., and Karkee, M. B.: Parametric study on simualted microtremors and its application to interpretation of microtremor records, J. Struct. Constr. Eng., AIJ, 535, 69-78, 2000.

Tokimatsu, K.: Geotechnical site characterization using surface waves, Proc. of the First Int. Conf. on Earthquake Geotech. Eng. IS-Tokyo'95, Tokyo, 1333-1368, 1995. 